\title{
Analisis Daya Saing untuk Meningkatkan Kualitas Layanan Terhadap Pelanggan dengan Pendekatan CRM di CV. BLITZSPOT
}

\author{
Muhammad Suryadi1,*, Dian Dharmayanti2 \\ 1,2 Program Studi Teknik Informatika FTIK Universitas Komputer Indonesia \\ (corresponding author) surya.march95@gmail.com*)
}

\begin{abstract}
CV. Blitzspot is a company that engaged in providing internet service (Internet Service Provider), which is headquartered in Komplek Padasuka Indah Ruko Block A-1, Cimahi, West Java. Based on interviews and observations on CV. Blitzspot transaction data, CV. Blitzspot customers who conduct transactions each year has decreased, it's because consumers often compare the services offered by competitors CV. Blitzspot and eventually moved to that competitor. If that problem is not resolved, CV. Blitzspot consumers will decrease each year and always moved to CV. Blitzspot competitor.Mr. Muhammad Adra as the president director of CV. Blitzspot, wants to analyzing competitiveness to determine what services that will be provided to the customers and defining a strategy to retain CV. Blitzspot customers. Type of CRM that used is Analytical CRM, Framework CRM that used is Social CRM, Method that use for Competitiveness Analysis is Porter's Diamond Analysis Model and Method for grouping customer is LRFM.Based on test results and discussion that has been made, it can be concluded that president director can analyzing competitiveness of CV. Blitzspot using Berlian Porter to improve the quality of service on CV. Blitzspot customers.
\end{abstract}

Keyword-crm, porter's diamond, Irfm, customer grouping, competitiveness analysis

Intisari- CV. Blitzspot adalah perusahaan yang bergerak di bidang jasa penyediaan layanan internet (internet service provider), yang berkantor pusat di Komplek Padasuka Indah Ruko Blok A-1, Cimahi, Jawa Barat. Berdasarkan hasil wawancara dan hasil observasi pada data transaksi CV. Blitzspot, konsumen CV. Blitzspot yang melakukan transaksi tiap tahunnya selalu berkurang, hal ini dikarenakan konsumen sering membandingkan layanan-layanan yang ditawarkan oleh para pesaing CV. Blitzspot. Bila permasalahan tersebut belum teratasi, konsumen CV. Blitzspot akan menurun tiap tahunnya dan akan selalu berpindah ke pesaing CV. Blitzspot.Direktur Utama CV. Blitzspot ingin menganalisis daya saing untuk menentukan layanan-layanan yang akan diberikan kepada pelanggan CV. Blitzspot dan penentuan strategi untuk mempertahankan konsumen CV. Blitzspot. Jenis CRM yang digunakan adalah CRM Analitikal, Framework CRM yang digunakan adalah Social CRM, Metode Analisis daya saing yang digunakan adalah Model Analisis Berlian Porter dan Metode Pengelompokkan Pelanggan yang digunakan adalah Metode LRFM.Berdasarkan hasil pengujian dan pembahasan yang telah dibuat, maka dapat ditarik kesimpulan bahwa Direktur Utama dapat menganalisis daya saing CV. Blitzspot dengan menggunakan Berlian Porter untuk meningkatkan kualitas layanan terhadap pelanggan CV. Blitzspot.

Kata Kunci-crm, berlian porter, Irfm, pengelompokkan pelanggan, daya saing

I. PENDAHULUAN

CV. Blitzspot adalah perusahaan yang bergerak di bidang jasa penyediaan layanan internet (internet service provider), yang berkantor pusat di Komplek Padasuka Indah Ruko Blok A-1, Cimahi, Jawa Barat. Perusahaan yang berdiri sejak tahun 2009 ini, mempunyai total staff 9 orang dan terbagi menjadi 5 bagian. Bagian-bagian pada CV. Blitzspot yaitu Network Teknisi, Network Operation Control (NOC), Admin/Finance/Accounting, Komisaris, dan Direktur Utama.

Berdasarkan hasil wawancara yang dilakukan kepada Bapak Muhammad Adra sebagai Direktur Utama CV. Blitzpot dan juga hasil observasi terhadap data transaksi, pada tahun 2014 CV. Blitzspot mempunyai 123 konsumen yang terfokus di daerah Cimahi dan sekitarnya. Akan tetapi, tiap tahunnya jumlah konsumen yang melakukan transaksi semakin berkurang. Pada tahun 2015, jumlah konsumen yang sudah mulai melakukan transaksi pada tahun 2014, berkurang menjadi 93 konsumen. Pada bulan Juni Tahun 2016, dari 93 konsumen hanya menyisakan 75 konsumen saja yang masih menjadi pelanggan di CV. Blitzspot. 
Menurut Bapak Muhammad Adra selaku Direktur Utama CV. Blitzspot, alasan utama konsumen berhenti menggunakan jasa CV. Blitzspot yaitu banyaknya konsumen yang lebih memilih pindah ke pesaing CV. Blitzspot lainnya, hal ini dikarenakan, para konsumen tersebut sering membandingkan layanan-layanan yang ditawarkan oleh para pesaing CV. Blitzspot. CV Blitzspot saat ini memiliki layanan yang terbatas untuk para konsumen yang sudah menjadi pelanggan CV. Blitzspot. Layanan tersebut yaitu sebatas pelayanan keluhan gangguan internet lewat SMS atau Telepon saja.

Direktur Utama CV. Blitzspot mengaku kesulitan dalam menganalisis daya saing untuk menentukan layanan-layanan apa saja yang akan diberikan kepada pelanggan dan menentukan strategi untuk mempertahankan pelanggan yang berpotensi menjadi pelanggan setia CV. Blitzspot ataupun mempertahankan pelanggan setia CV. Blitzspot agar tidak pindah ke pesaing CV. Blitzspot lainnya (Pelanggan adalah orang yang sudah pernah bertransaksi dan masih berlangganan dengan CV. Blitzspot), hal ini dikarenakan jumlah konsumen baru dan total konsumen CV. Blitzspot yang tiap tahunnya selalu bertambah, mengakibatkan Direktur Utama sulit untuk menentukan karakteristik tiap konsumennya (Konsumen adalah orang yang sudah pernah bertransaksi, tetapi sudah berhenti berlangganan dengan CV. Blitzspot). Bila permasalahan tersebut belum teratasi, konsumen yang memiliki potensi untuk menjadi pelanggan setia CV. Blitzspot atau konsumen yang sudah menjadi pelanggan setia CV. Blitzspot, akan menurun tiap tahunnya dan akan selalu berpindah ke pesaing CV. Blitzspot.

Berdasarkan permasalahan yang telah diuraikan diatas, maka dari itu penulis tertarik untuk melakukan suatu Analisis Daya Saing untuk meningkatkan Kualitas Layanan terhadap Pelanggan dengan pendekatan CRM di CV. Blitzspot berbasis web untuk menjadi pembina dan pengontrol hubungan antara perusahaan dan pelanggan. Jenis CRM yang digunakan adalah CRM analitikal. Diharapkan dengan adanya analisis daya saing ini, dapat membantu menyelesaikan permasalahan terhadap pelanggan yang terjadi di CV. Blitzspot.

Adapun tujuan yang akan dicapai dari penelitian tugas akhir ini, yaitu :

1. Membantu Direktur Utama CV. Blitzspot dalam menganalisis daya saing untuk menentukan layanan-layanan yang akan diberikan kepada pelanggan CV. Blitzspot agar pelanggan tersebut tidak pindah ke pesaing CV. Blitzspot dengan menggunakan Analisis Berlian Porter.

2. Membantu CV. Blitzspot untuk menentukan strategi dalam mempertahankan konsumen yang memiliki potensi untuk menjadi pelanggan setia CV. Blitzspot dan mempertahankan pelanggan setia CV. Blitzspot.

3. Memudahkan konsumen atau pelanggan untuk mengetahui informasi seputar layanan-layanan baru yang akan diberikan oleh CV. Blitzspot.

\section{METOdOLOGI PENELITIAN}

Metodologi Penelitian merupakan suatu proses tahapan yang digunakan untuk memecahkan suatu masalah yang logis, memerlukan data-data untuk mendukung terlaksananya suatu penelitian. Metodologi Penelitian pada Analisis Daya Saing untuk Meningkatkan Kualitas Layanan terhadap Pelanggan dengan pendekatan CRM di CV. Blitzspot, terdapat pada Gambar. 1. 




Gambar. 1 Metodologi Penelitian

III. TINJAUAN PUSTAKA

Sistem adalah suatu jaringan kerja dari prosedur-prosedur yang saling berhubungan, berkumpul bersama-sama untuk melakukan suatu kegiatan atau untuk menyelesaikan suatu sasaran yang tertentu [1]. Informasi adalah data yang diolah menjadi bentuk yang lebih berguna dan lebih berarti bagi yang menerimanya. Sumber dari informasi adalah data. Data merupakan bentuk jamak dari bentuk tunggal datum atau data item. Data adalah kenyataaan yang menggambarkan suatu kejadian-kejadian dan kesatuan nyata [1]. Sistem Informasi adalah suatu jaringan kerja dari prosedur-prosedur yang saling berhubungan untuk melakukan suatu kegiatan atau untuk menyelesai satu sasaran yang tertentu dan didalamnya terdapat data-data yang diolah menjadi bentuk yang lebih berguna bagi penerimanya.

CRM adalah strategi bisnis dengan menerapkan teknologi informasi pada perusahaan secara komprehensif, handal, dan terintegrasi berdasarkan sudut pandang member, dengan begitu semua proses dan interaksi saling membantu mempertahankan dan mengembangkan hubungan yang bermanfaat [2]. Pengimplementasian konsep CRM yang baik adalah mengorganisasikan proses CRM disekitar pelanggan dan tidak hanya pada fungsi internal perusahaan [3]. Terdapat tiga tahapan dalam Customer Relationship Management, yaitu Acquire, Retain, dan Enhance. Jenis-jenis dari CRM, yaitu [4] Strategi (Strategic), Operasional (Operational), Analitis (Analytical), Kolaborasi (Collaborative). 
Framework adalah kerangka kerja yang dapat digunakan untuk mengembangkan sistem CRM. Inti dari revolusi teknologi informasi CRM adalah teknologi berbasis web dimana perusahaan diberikan kesempatan untuk memilih bagaimana perusahaan berinteraksi dengan pelanggan. Teknologi berbasis web ini memungkinkan perusahaan membangun hubungan yang baik dengan pelanggan daripada sebelumnya dengan cara manual. Penggunaan web memiliki kemampuan untuk merespon langsung permintaan pelanggan dan menyediakan kebutuhan pelanggan dengan interaktif selain itu perusahaan dapat memanfaatkan biaya yang rendah dengan layanan yang berkualitas [5].Dalam menetapkan fitur CRM secara tepat diperlukan framework sebagai acuan. Framework CRM yang digunakan yaitu Social CRM.

Social CRM adalah filosofi dan strategi bisnis yang didukung oleh platform teknologi, aturan bisnis, proses, dan sosial karakteristik, yang dirancang untuk melibatkan pelanggan untuk memberikan nilai yang saling menguntungkan dalam lingkungan bisnis terpercaya dan transparan. Social CRM tidak mengenali adanya pelanggan pasif yang interaksinya hanya diawali dari sebuah transaksi dengan perusahaan. Sebuah transaksi bukanlah suatu artifak yang menjadi asal mula terjadinya interaksi. Sebaliknya, transaksi seharusnya adalah hasil akhir dari proses pengelolaan hubungan antara pelanggan dan perusahaan yang dibangun berdasarkan sebuah interaksi yang baik [6].Framework CRM yang diguanakan dapat dilihat pada Gambar. 2.

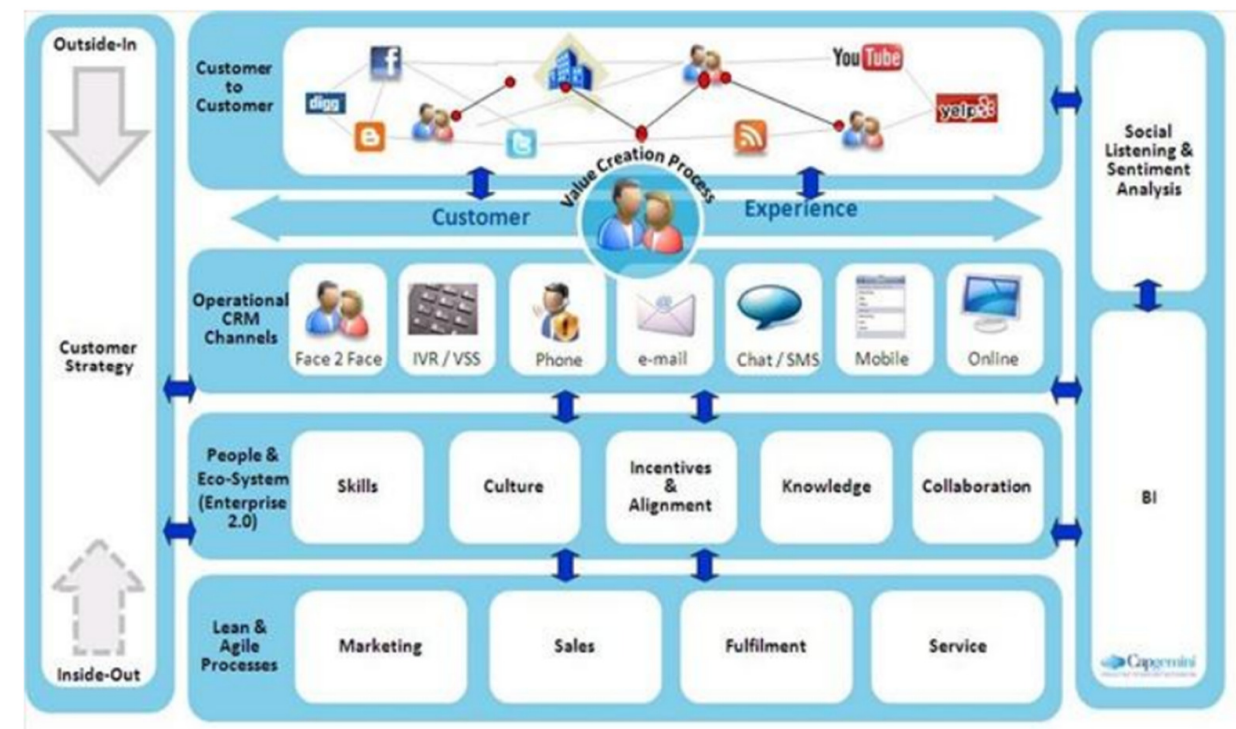

Gambar. 2 Framework CRM

Penjelasan layer pada framework CRM:

1. Layer Customer Strategy : Layer awal dimana perusahaan menentukan strategi untuk menjangkau pelanggan. Layer ini memiliki attribut inside-out dan outside-in. Inside-out yang berarti strategi yang berasal dari perusahaan itu sendiri dan diterapkan kepada pelanggan, dan outside-in yang berarti strategi yang diterapkan oleh perusahaan berdasarkan saran atau kritik yang diberikan oleh pelanggan.

2. Layer Customer to Customer: Layer ini menjelaskan bagaimana cara pelanggan berbagi informasi tentang perusahaan kepada orang lain atau perusahaan lain.

3. Layer Customer Experience : Layer yang merupakan akumulasi pengalaman pelanggan terhadap perusahaan. Pada tahap ini dalam sistem akan menampilkan pelanggan mana yang telah menjalin hubungan kerjasama dengan pihak perusahaan dan memiliki loyalitas tinggi dengan ketentuan pelanggan sudah memenuhi masa periode tertentu.

4. Layer Operational CRM Channels : Layer ini merupakan tahapan berkomunikasi dan berinteraksi antara perusahaan dan pelanggan.

5. Layer People \& Eco-System : Layer ini menunjukkan SDM yang kompeten untuk menjalankan sistem CRM yang akan dibangun.

6. Layer Lean \& Agile Processes : Layer ini berhubungan dengan semua proses bisnis yang ada kaitannya dengan pelanggan. 
Kata daya dalam kalimat daya saing bermakna kekuatan, dan kata saing berarti mencapai lebih dari yang lain, atau beda dengan yang lain dari segi mutu, atau memiliki keunggulan tertentu. Artinya daya saing dapat bermakna kekuatan untuk berusaha menjadi unggul dalam hal tertentu yang dilakukan seseorang, kelompok atau institusi tertentu [7].

Keunggulan bersaing merupakan kegiatan spesifik yang dikembangkan oleh perusahaan agar lebih unggul dibandingkan dengan pesaingnya [8]. Kata unggul di atas, merupakan posisi relatif organisasi terhadap organisasi lainnya [7]. Metode analisis daya saing yang akan digunakan adalah Berlian Porter.

Model Competitiveness Diamond, mengatakan bahwa industri di suatu daerah unggul bukanlah dari kesesuaian sendiri tetapi merupakan kesuksesan kelompok dengan adanya keterkaitan antar perusahaan dan institusi yang mendukung. Pada klaster industri, perusahaan-perusahaan yang terlibat tidak hanya perusahaan besar dan menengah, tetapi juga perusahaan kecil. Porter memperkenalkan teori kemampuan kompetisi suatu negara yang di gambarkan dalam model berlian seperti yang dilihat pada Gambar. 3[9].

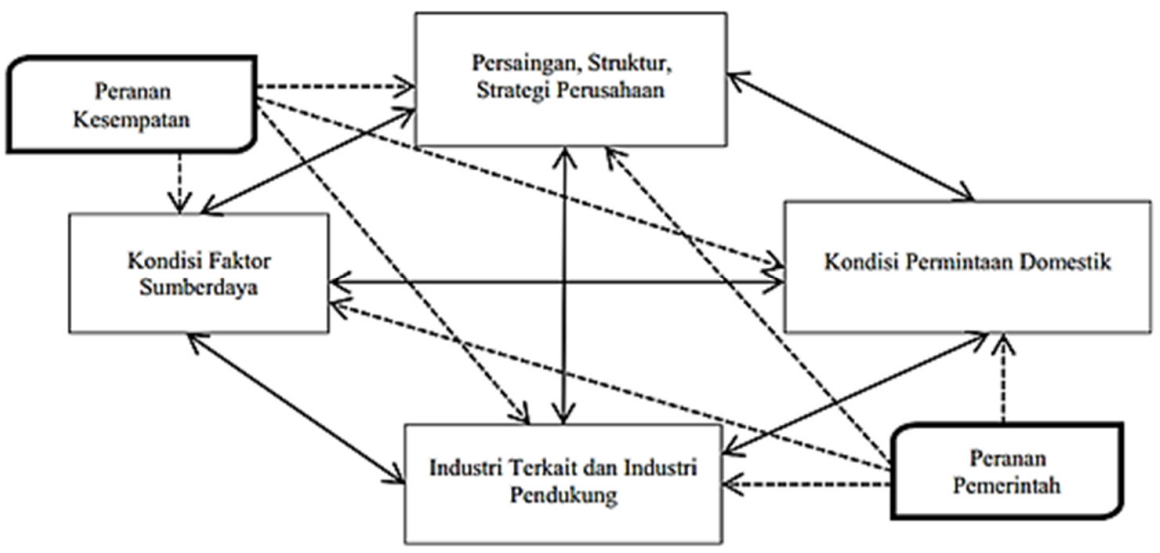

Gambar. 3 Model Berlian Porter

1. Kondisi Faktor Sumberdaya

Keadaan faktor-faktor produksi dalam suatu industri seperti tenaga kerja dan infrastruktur. Ada 4 cakupan sumber daya, yaitu Sumberdaya Manusia, Sumberdaya Fisik/Alam, Sumberdaya IImu Pengetahuan dan Teknologi, dan Sumberdaya Modal.

2. Kondisi Permintaan Domestik

Permintaan di dalam negeri terhadap produk atau layanan di negara tersebut. Permintaan dalam negeri merupakan aspek yang mempengaruhi arah pengembangan faktor awalan keunggulan kompetitif sector industri. Inovasi dan kemajuan teknologi dapat terinspirasi oleh kebutuhan dan keinginan konsumen.

3. Industri Terkait dan Industri Pendukung

Keberadaan industri pemasok atau industri pendukung yang mampu bersaing secara internasional. Faktor ini menggambarkan hubungan dan dukungan antar industri.

4. Stretagi Perusahaan, Struktur dan Persaingan

Strategi yang dianut perusahaan pada umumnya, struktur industri dan keadaan kompetisi dalam suatu industri domestik.

5. Faktor Pemerintah

Pemerintah pada semua tingkatan pemerintahan dapat meningkatkan atau memperlemah keunggulan nasional. Peran pemerintah terutama dalam membentuk kebijakan yang mempengaruhi komponen-komponen dalam Berlian Porter.

6. Faktor Kesempatan

Perkembangan yang berada di luar kendali perusahaan-perusahaan dan biasanya juga di luar kendali pemerintah pada suatu bangsa. 
Pengelompokkan Pelanggan adalah pembagian pasar ke dalam kelompok-kelompok pelanggan spesifik yang memiliki karakteristik sama. Metode pengelompokkan pelanggan yang akan digunakan adalah LRFM.

Metode yang sering digunakan untuk menentukan apakah seorang pelanggan berharga (valuable customer) adalah Recency, Frequency, dan Monetary (RFM) yaitu dengan melihat pembelian pelanggan yang paling akhir dilakukannya dari segi waktu (recency), yang paling sering membeli (frequency), dan yang paling tinggi nilai rupiahnya (monetary) [10].Formula R/F/M bukanlah penemuan baru. R/F/M telah menjadi standar bagi perusahaan yang menjual merchandise sejak setengah abad lampau. Pada awalnya formula ini dikembangkan oleh George Cullinan untuk perusahaannya yang bernama Alden"s. Formula tersebut kemudian diikuti oleh banyak perusahaan lain, termasuk raksasa supermarket di Amerika seperti Sears Roebuck dan Montgomery Ward. Kemudian formula tersebut ditambahkan atribut atau variabel $L$ sebagai pendukung dalam pengelompokan. Formula L/R/F/M tidak harus selalu sama antara satu pemasar dengan pemasar lainnya, tergantung pada prioritasnya terhadap 4 (empat) variable yaitu Length, Recency, Frequency, Monetary. Berdasarkan hasil analisis LRFM terhadap 4 variabel yang telah dilakukan, maka selanjutnya adalah mengelompokkan pelanggan berdasarkan skor LRFM. Terdapat 5 ketagori pelanggan berdasarkan skor LRFM. Kategori Pelanggan dapat dilihat pada Tabel I.

Tabel I. Kategori Pelanggan Berdasarkan Poin LRFM

\begin{tabular}{|c|c|c|}
\hline No & Kategori Pelanggan & Keterangan \\
\hline 1 & Pelanggan Loyal & $\begin{array}{l}\text { Pelanggan Loyal adalah konsumen yang masih menjadi pelanggan Blitzspot, dimana konsumen tersebut sudah } \\
\text { berlangganan minimal } 2 \text { tahun, sudah melakukan transaksi minimal } 16 \text { kali dan total transaksinya minimal } 2,5 \\
\text { juta rupiah. } \\
\text { Grup Pelanggan Berdasarkan Poin LRFM pada Kategori Pelanggan Loyal, Terdiri dari : } \\
\text { 1. LRFM, } \uparrow \downarrow \uparrow \uparrow\end{array}$ \\
\hline 2 & Pelanggan Potensial & $\begin{array}{l}\text { Pelanggan Potensial adalah konsumen yang masih menjadi pelanggan Blitzspot, dimana konsumen tersebut } \\
\text { sudah berlangganan minimal } 2 \text { tahun dan minimal mempunyai } 1 \text { dari } 2 \text { hal berikut : } \\
\text { 1. Jumlah Transaksi yang dilakukan minimal } 16 \text { kali } \\
\text { 2. Total Transaksi sudah mencapai } 2,5 \text { juta } \\
\text { Grup Pelanggan Berdasarkan Poin LRFM pada Kategori Pelanggan Potensial, Terdiri dari : } \\
\text { 1. } \quad \text { LRFM, } \uparrow \downarrow \uparrow \downarrow \\
\text { 2. } \quad \text { LRFM, } \uparrow \downarrow \downarrow \uparrow\end{array}$ \\
\hline 3 & Pelanggan Baru & $\begin{array}{l}\text { Pelanggan Baru adalah konsumen yang baru menjadi pelanggan Blitzspot, dimana konsumen tersebut } \\
\text { lamanya berlangganan belum mencapai } 2 \text { tahun. Konsumen yang sudah berlanggan } 2 \text { tahun, tetapi jumlah } \\
\text { transaksi masih dibawah } 16 \text { kali dan total transaksinya dibawah } 2,5 \text { juta rupiah, juga masuk dalam kategori } \\
\text { Pelanggan Baru. } \\
\text { Grup Pelanggan Berdasarkan Poin LRFM pada Kategori Pelanggan Baru, Terdiri dari : } \\
\text { 1. LRFM, } \downarrow \downarrow \downarrow \uparrow \\
\text { 2. } \quad \text { LRFM, } \downarrow \downarrow \uparrow \downarrow \\
\text { 3. } \quad \text { LRFM, } \downarrow \downarrow \uparrow \uparrow \\
\text { 4. } \quad \text { LRFM, } \downarrow \downarrow \downarrow \downarrow \\
\text { 5. } \quad \text { LRFM, } \uparrow \downarrow \downarrow \downarrow\end{array}$ \\
\hline 4 & Konsumen Potensial & $\begin{array}{l}\text { Konsumen Potensial adalah konsumen yang sudah berhenti berlanggan menjadi Blitzspot. Akan tetapi selama } \\
\text { berlangganan, konsumen tersebut sudah berlangganan minimal } 2 \text { tahun atau minimal mempunyai } 1 \text { dari } 2 \text { hal } \\
\text { berikut : } \\
\text { 1. Jumlah Transaksi yang dilakukan minimal } 16 \text { kali } \\
\text { 2. Total Transaksi sudah mencapai } 2,5 \text { juta } \\
\text { Grup Pelanggan Berdasarkan Poin LRFM pada Kategori Konsumen Potensial, Terdiri dari : } \\
\text { 1. LRFM, } \uparrow \uparrow \uparrow \uparrow \\
\text { 2. } \quad \text { LRFM, } \uparrow \uparrow \uparrow \downarrow \\
\text { 3. } \quad \text { LRFM, } \uparrow \uparrow \downarrow \uparrow \\
\text { 4. LRFM, } \quad \text { L } 1 \uparrow \\
\text { 5. LRFM, } \quad \text { L } \uparrow \uparrow \\
6 . \quad \text { LRFM, } \downarrow \uparrow \uparrow \uparrow\end{array}$ \\
\hline 5 & $\begin{array}{l}\text { Konsumen tidak } \\
\text { potensial }\end{array}$ & $\begin{array}{l}\text { Konsumen tidak potensial adalah konsumen yang sudah berhenti menjadi pelanggan Blitzspot. Konsumen } \\
\text { tersebut selama berlangganan, jumlah transaksi yang dilakukan masih dibawah } 16 \text { kali ataupun total } \\
\text { transaksinya masih dibawah 2,5 juta rupiah. } \\
\text { Grup Pelanggan Berdasarkan Poin LRFM pada Kategori Konsumen tidak potensial, Terdiri dari : } \\
\text { 1. LRFM, } \downarrow \uparrow \downarrow \downarrow \\
\text { 2. } \quad \text { LRFM, } \uparrow \uparrow \downarrow \downarrow\end{array}$ \\
\hline
\end{tabular}




\section{HASIL DAN ANALISA}

\section{A. Analisis Framework CRM}

Analisis Sistem yang sedang berjalan merupakan suatu analisis untuk mengetahui sistem yang sedang berjalan pada suatu perusahaan yang akan dikaitkan dengan kesesuaian dalam penelitian ini. Sistem yang sedang berjalan pada CV. Blitzspot akan dipetakan ke Framework CRM yang akan digunakan. Setelah dipetakan, Tiap Layer di Framework CRM pada sistem yang sedang berjalan nantinya akan di evaluasi untuk menentukan Framework CRM yang akan diterapkan. Gambaran layer Framework CRM beserta komponen-komponen bagian dalam layer pada sistem yang sedang berjalan di CV. Blitzspot, dapat dilihat pada Gambar. 4.

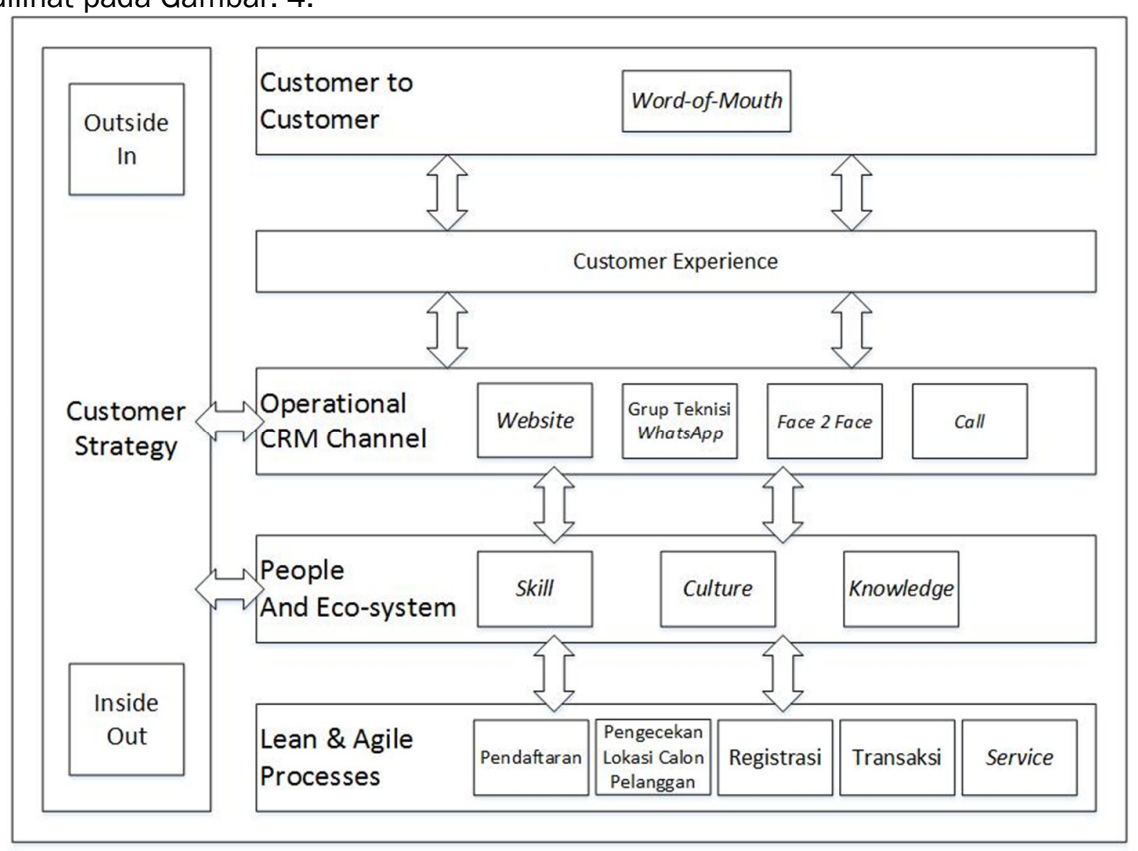

Gambar. 4 Framework CRM yang sedang berjalan

Evalusi Sistem yang sedang berjalan ditujukan untuk mengetahui letak kelebihan dan kekurangan dari suatu sistem yang saat ini sedang berjalan pada suatu perusahaan.. Berdasarkan Sistem yang sedang berjalan di CV. Blitzspot, maka dapat di evaluasi kelebihan dan kekurangan dari sistem tersebut. Kesimpulan dan solusi dari evaluasi sistem yang sedang berjalan tersebut yaitu:

1. Pada layer customer strategy di attribut outside-in, Diperlukan suatu analisis daya saing untuk menentukan strategi yang tepat dalam meningkatkan kualitas layanan terhadap pelanggan Blitzspot. Metode analisis daya saing yang digunakan adalah Analisis Berlian Porter. Komponen yang diambil di analisis berlian porter untuk solusi pada layer customer strategy, yaitu Strategi Perusahaan, Struktur dan Persaingan, Faktor Kesempatan

2. Pada layer customer experience, Diperlukan suatu analisis pengelompokkan pelanggan untuk mengelompokkan pelangggan menggunakan lebih dari dua faktor. Metode Pengelompokkan Pelanggan yaitu menggunakan Metode LRFM (Length, Recency, Frequency, Monetary).

3. Pada layer people and eco-system, Diperlukan adanya suatu analisis daya saing untuk mendukung kelebihan dari Layer People and Eco-system terhadap para pesaingnya. Metode analisis daya saing yang digunakan adalah Analisis Berlian Porter. Komponen yang diambil di analisis berlian porter untuk solusi pada layer people and eco-system, yaitu Kondisi Faktor Sumberdaya.

Berdasarkan evaluasi sistem yang sedang berjalan saat ini, maka dapat diterapkan layer framework untuk pembangunan aplikasi CRM ini. Berikut adalah penjelasan komponen layer framework yang diusulkan.

1. Layer Customer Strategy : Pada Outside-in, Strategi pendekatan dengan pelanggan yang berasal dari pelanggan yang akan diterapkan yaitu CV. Blitzspot terlebih dahulu melakukan analisis daya saing untuk melihat tingkat daya saing mereka terhadap pesaing lainnya untuk mentukan strategi Outside-in yang akan dilakukan oleh CV. Blitzspot. Metode analisis daya saing yang akan digunakan adalah Analisis Berlian Porter. Pada Inside-out, Strategi pendekatan dengan pelanggan CV. Blitzspot dilakukan dengan cara memberikan informasi perusahaan melalui situs Blitzspot yaitu blitzspot.net. dan sosial media, yaitu facebook dan twitter. 
2. Layer Customer to Customer: CV. Blitzspot melakukan strategi promosi Word-of-Mouth, dimana pelanggan akan berbagi informasi secara lisan maupun tertulis, online maupun offline, tentang perusahaan ke calon pelanggan.

3. Layer customer experience : Pada layer ini, pencatatan data pelanggan dan transaksi pelanggan akan dilakukan dengan aplikasi database MySQL. Setelah itu, berdasarkan data transaksi pelanggan, akan dilakukan pengelompokkan pelanggan untuk menentukan kelompok-kelompok pelanggan yang nantinya pengelompokkan tersebut akan menjadi bahan untuk layer case \& feedback. Metode yang akan digunakan untuk pengelompokkan pelanggan adalah LRFM.

4. Layer operational CRM Channels : Pada layer ini, terdapat 5 channels yang digunakan oleh Blitzspot untuk berhubungan dengan pelanggan, yaitu Website, Grup Teknisi WhatsApp, Social Media, dan Hotline.

5. Layer People and Eco-System : Pada layer ini, CV. Blitzspot memfokuskan pegawainya agar menjadi SDM yang kompeten dengan 3 hal, yaitu Skills, Knowledge, dan Culture.

6. Layer Lean \& Agile Processes : Pada layer ini, proses-proses bisnis yang dilakukan oleh Blitzspot yang berhubungan dengan pelanggan, meliputi Pendaftaran, Pengecekan Lokasi Calon Pelanggan, Registrasi, Transaksi dan Service.

7. Layer Case \& Feedback : Komponen usulan untuk Layer Case \& Feedback, yaitu membentuk suatu layanan lebih untuk pelanggan Blitzspot berdasarkan hasil pengelompokkan pelanggan yang dilakukan pada Layer Customer Experience.

Berdasarkan penjelasan layer framework beserta komponen-komponen bagian dalam layer framework CRM yang akan diterapkan pada CV. Blitzspot, gambaran framework CRM pada CV. Blitzspot dapat dilihat pada Gambar 5.

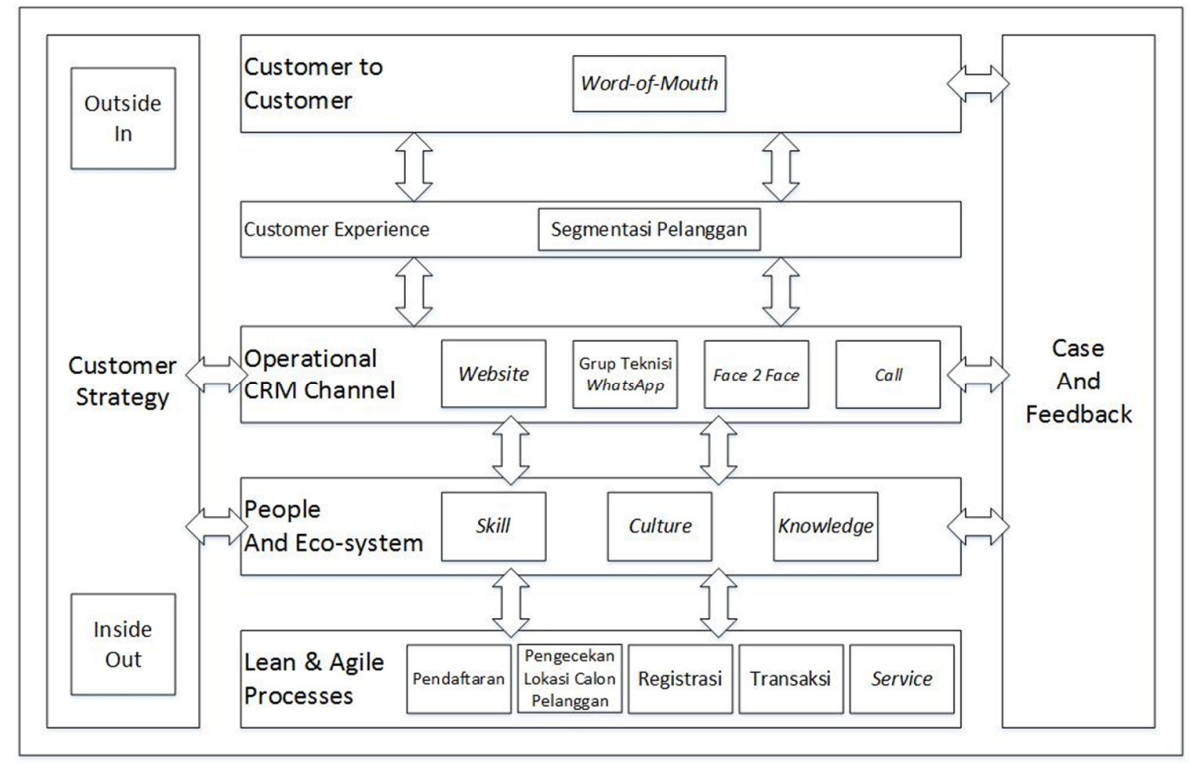

Gambar. 5 Framework CRM yang akan diterapkan

\section{B. Analisis Daya Saing dengan Berlian Porter}

Analisis Daya Saing disini bertujuan untuk mengetahui tingkat daya saing yang dimiliki oleh CV. Blitzspot terhadap perusahaan pesaing lainnya yang berada di daerah Cimahi. Metode yang digunakan untuk menganalisis daya saing adalah dengan Metode Analisis Berlian Porter. Komponen yang akan digunakan pada Berlian Porter yaitu Strategi Perusahaan, Struktur dan Persaingan, Kondisi Faktor Sumberdaya, Faktor Pemerintah dan Faktor Kesempatan.

Berikut adalah rincian dari daya saing CV. Blitzspot yang diterapkan ke Analisis Berlian Porter:

1. Kondisi Faktor Sumberdaya

Berikut adalah kondisi-kondisi faktor sumberdaya CV. Blitzspot yang mencakup Sumberdaya Manusia (SDM), Sumberdaya Fisik/Alam, Sumberdaya Ilmu Pengetahuan dan Teknologi, dan Sumberdaya Modal:

a. Jumlah tenaga kerja Blitzspot yang cukup untuk melayani pelanggan, terutama pada bidang Network Engineer. Hal ini didukung berdasarkan wawancara terhadap Direktur Utama CV. Blitzspot yang menyatakan bahwa saat ini CV. Blitzspot belum mengalami masalah yang serius dalam melayani pelanggan-pelanggan mereka yang saat ini berjumlah 203 pelanggan. 
b. Etika kerja tiap pegawai Blitzspot yang disiplin. Hal ini didukung berdasarkan wawancara terhadap Direktur Utama CV. Blitzspot yang menyatakan bahwa, etika yang dimiliki oleh pegawai-pegawainya saat ini masih bagus. Masalahmasalah yang dilakukan pegawainya pada bagian etika, seperti telat kerja, human-error dan tingkah buruk dalam melayani pelanggan, masih sangat jarang terjadi.

c. Ketrampilan yang dimiliki tiap pegawai Blitzspot dalam menguasai bidang pekerjaannya masing-masing. Bapak Muhammad Adra selaku Direktur Utama CV. Blitzspot menyatakan bahwa, seluruh pegawai Blitzspot saat ini sudah memenuhi syarat minimal sebagai pegawai Blitzspot sesuai dengan bidang pekerjaannya.

2. Strategi Perusahaan, Struktur dan Persaingan

Berikut adalah faktor-faktor daya saing Blitzspot dari segi Strategi Perusahaan, Struktur dan Persaingan:

a. Strategi Blitzspot yang masih terbatas, terutama dalam hal mempertahankan pelanggannya. Saat ini CV. Blitzspot masih belum mempunyai strategi khusus untuk mempertahankan pelanggannya. Layanan yang saat ini diberikan masih terbatas pada pelayanan keluhan gangguan internet lewat SMS atau Telepon saja.

b. Persaingan dari pesaing-pesaing yang sudah mempunyai nama di tingkat nasional, selalu memberikan tekanan ke Blitzspot dan terus melakukan inovasi baru untuk meningkatkan daya siangnya. Contoh inovasi yang dilakukan yaitu menambahkan layanan tv kabel dalam paket internet mereka.

c. Struktur organisasi Blitzspot yang sudah bagus, dimana tiga komisaris membantu untuk mengawas perusahaan dan bidang yang memiliki banyak pegawai difokuskan ke bidang Network Engineer. Bidang Network Engineer mempunyai banyak peran secara langsung dalam berinteraksi dengan pelanggan Blitzspot.

3. Faktor Pemerintah

Faktor Pemerintah yang berada di ruang lingkup Blitzspot adalah Bentuk Perusahaan Blitzspot yang saat ini sudah menjadi Perseroan Terbatas (PT). Dimana, PT adalah bentuk perusahaan yang sudah berbadan hukum.

4. Faktor Kesempatan

Berikut adalah faktor-faktor kesempatan yang berada di ruang lingkup Blitzspot:

a. Kondisi permintaan terhadap internet yang tiap tahunnya selalu meningkat, menjadikan kesempatan untuk Blitzspot dalam mengembangkan usahanya.

b. Pengguna Jasa ISP yang menginginkan adanya layanan teknis 24 jam, untuk mengatasi masalah-masalah yang berhubungan dengan internet dimana masalah-masalah tersebut muncul tidak menentu waktunya.

c. Pengguna Jasa ISP yang menginginkan harga layanan internet murah dan bersifat unlimited.

d. Pengguna Jasa ISP yang menginginkan suatu reward apabila sudah lama menggunakan suatu layanan internet.

Hasil Analisis Berlian Porter akan terlihat pada keterkaitannya antara komponen-komponennya beserta kesimpulan antar komponen tersebut. Keterkaitan antar komponen Berlian Porter pada Blitzspot dapat dilihat pada Tabel II.

Tabel II. Keterkaitan antara Komponen Berlian Porter

\begin{tabular}{|c|c|c|c|}
\hline Komponen A & Komponen B & $\begin{array}{l}\text { Keterkaitan antar } \\
\text { Komponen }\end{array}$ & Kesimpulan \\
\hline $\begin{array}{l}\text { Kondisi Faktor } \\
\text { Sumberdaya }\end{array}$ & $\begin{array}{l}\text { Strategi Perusahaan, } \\
\text { Struktur dan } \\
\text { Persaingan }\end{array}$ & Mendukung & $\begin{array}{l}\text { Keterkaitan antara dua komponen masih cukup mendukung. } \\
\text { Faktor Sumberdaya Blitzspot yang masih bisa mendukung untuk } \\
\text { memenuhi strategi perusahaan, struktur dan perusahaan, } \\
\text { begitupun sebaliknya. }\end{array}$ \\
\hline Faktor Kesempatan & $\begin{array}{l}\text { Kondisi Faktor } \\
\text { Sumberdaya }\end{array}$ & Mendukung & $\begin{array}{l}\text { Hampir semua kesempatan yang diberikan oleh pengguna } \\
\text { Jasa ISP bisa terpenuhi oleh Blitzspot. Keterkaitan ini dapat } \\
\text { ditingkatkan apabila Blitzspot bisa selalu mengatur jumlah tenaga } \\
\text { kerja sesuai dengan jumlah pelanggan yang dimiliki mereka. }\end{array}$ \\
\hline Faktor Kesempatan & $\begin{array}{l}\text { Strategi Perusahaan, } \\
\text { Struktur dan } \\
\text { Persaingan }\end{array}$ & Belum Mendukung & $\begin{array}{l}\text { Adanya strategi-strategi dari pesaing CV. Blitzspot dengan } \\
\text { membuat layanan-layanan baru yang menarik pelanggan, seperti } \\
\text { penambahan layanan tambahan berupa tv kabel dipaketkan } \\
\text { dengan layanan internetnya. Adanya peningkatan inovasi-inovasi } \\
\text { baru dari pesaing Blitzspot tersebut mengakibatkan Blitzspot harus } \\
\text { selalu membuat strategi-strategi baru untuk mempertahankan } \\
\text { pelanggannya. }\end{array}$ \\
\hline Faktor Pemerintah & $\begin{array}{l}\text { Strategi Perusahaan, } \\
\text { Struktur dan } \\
\text { Persaingan }\end{array}$ & Mendukung & $\begin{array}{l}\text { Dukungan landasan hukum oleh pemerintah, dikarenakan } \\
\text { bentuk perusahaan Blitzspot yang saat ini sudah menjadi PT, } \\
\text { dibandingkan dengan pesaing CV. Blitzspot dengan jenis layanan } \\
\text { internet yang sama (Wireless) yaitu Wastama Internet, yang bentuk } \\
\text { perusahaannya masih berupa CV. }\end{array}$ \\
\hline
\end{tabular}


Berdasarkan hasil dari keterkaitan antar komponen-konponen yang terdapat pada berlian porter, maka kesimpulankesimpulan yang bisa didapat dari analisis daya saing dengan berlian porter, yaitu:

1. Pemberian solusi berupa pengaturan jumlah pegawai mereka, yang disesuaikan dengan jumlah pelanggan mereka. Pemberian solusi tersebut bertujuan untuk meningkatkan daya saing pada komponen Kondisi Faktor Sumberdaya.

2. Pemberian solusi atau strategi yaitu pemberian suatu reward untuk pelanggan setia mereka. Pemberian strategi tersebut untuk meningkatkan keterkaitan antara Komponen Stretagi Perusahaan, Struktur dan Persaingan dan Faktor Kesempatan di Berlian Porter, yang saat ini masih belum mendukung.

3. Pemberian solusi berupa memperluas jaringan pencakupan layanan internet mereka, penambahan jenis layanan baru dan penambahan jenis bisnis mereka. Penambahan jenis layanan baru yaitu penambahan paket tv kabel selain paket internet. Penambahan jenis bisnis mereka seperti pengadaan CCTV, jasa konsultasi jaringan komputer dan perangkat lunak, dll. Pemberian solusi tersebut disesuaikan dari visi \& misi Blitzspot dan berguna untuk meningkatkan daya saing pada komponen Strategi Perusahaan, Struktur dan Persaingan.

\section{Analisis Pengelompokkan Pelanggan}

Dalam analisis pengelompokkanp pelanggan, tahapan yang akan dilakukan menggunakan metode LRFM ini dibuat dalam bentuk alur yang dijelaskan pada Gambar. 6. Berikut penjelasan dari tahapan-tahapan analisis pengelompokkan pelanggan menggunakan metode LRFM.

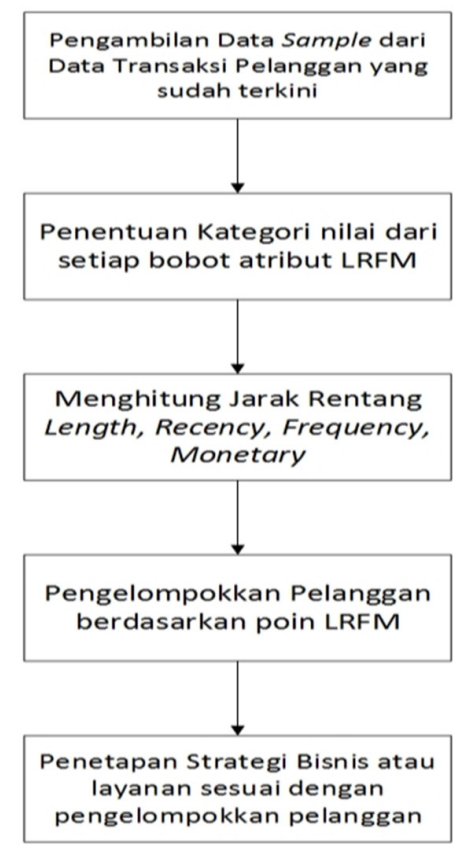

Gambar. 6 Tahapan Pengelompokkan Pelanggan Dengan LRFM

Pada tahap pertama, diambil data sample dari data transaksi pelanggan yang sudah terkini. Berikut adalah data sample transaksi pelanggan yang telah didefinisikan untuk perhitungan berdasarkan data transaksi pelanggan periode Januari 2014 - Juni 2016, transaksi tersebut dapat dilihat pada Tabel III. 
Tabel III. Pengambilan Data Sample dari Data Transaksi Pelanggan

\begin{tabular}{|c|c|c|c|c|c|c|}
\hline No & Nama & $\begin{array}{c}\text { Awal } \\
\text { Transaksi }\end{array}$ & Terakhir Transaksi & $\begin{array}{l}\text { Selisih Awal dan Terakhir } \\
\text { Transaksi }\end{array}$ & Jumlah Transaksi & Total Transaksi \\
\hline 1 & Adry82d & 4-Jan-14 & 2-Jun-16 & 30 & 28 & 3620000 \\
\hline 2 & Agi & 30-Apr-14 & 20-Jun-16 & 27 & 15 & 3750000 \\
\hline 3 & Alba property \& share & 10-Mar-15 & 14-Jun-16 & 16 & 16 & 1760000 \\
\hline 4 & April & 21-Mar-16 & 25-Jun-16 & 4 & 4 & 1000000 \\
\hline 5 & Gilang & $6-0 c t-15$ & 18-Jun-16 & 9 & 8 & 880000 \\
\hline 6 & Hendra Gunawan & 20-Jun-16 & 20-Jun-16 & 0 & 1 & 110000 \\
\hline 7 & Shindu & 10-Aug-15 & 15-Jun-16 & 11 & 11 & 3850000 \\
\hline 9 & Angga & 10-Feb-14 & 3-Sep-14 & 7 & 7 & 770000 \\
\hline
\end{tabular}

Pada tahapan kedua, dilakukan penentuan kategori nilai dari setiap bobot atribut LRFM. Penentuan kategori nilai ini menjadi dasar untuk membentuk pengelompokkan pelanggan. Setiap bobot attribut LRFM, terdapat 2 kategori nilai. Kategori nilai tersebut, yaitu kategori atas $(\uparrow)$ dan kategori bawah $(\downarrow)$. Berikut adalah pembagian kategori nilai dari masing-masing attribut LRFM:

1. Length : Kategori atas $(\uparrow)$, Length $>=20$ (bulan), Kategori bawah $(\downarrow)$, Length 20 (bulan)

2. Recency : Kategori atas $(\uparrow)$, Recency $>=30$ (hari), Kategori bawah ( $\downarrow$ ), Recency< 30 (hari)

3. Frequency : Kategori atas $(\uparrow)$, Frequency $>=16$ (kali), Kategori bawah ( $\downarrow$ ), Frequency< 16 (kali)

4. Monetary : Kategori atas $(\uparrow)$, Monetary $>=2500000$ (rupiah), Kategori bawah ( $\downarrow$ ), Monetary< 2500000 (rupiah)

Pada tahap ketiga dilakukan perhitungan untuk menentukan bobot dari setiap attribut domain. Berikut adalah perhitungan dari setiap bobot LRFM:

1. Length : Terakhir Transaksi - Awal Transaksi) / 30

2. Recency : Awal Bulan Setelah Akhir Periode - Terakhir Transaksi

3. Frequency : Jumlah Transaksi

4. Monetary : Total Transaksi

Setelah itu, dilakukan perhitungan poin pelanggan. Perhitungan poin pelanggan dapat dilihat pada Tabel IV.

Tabel IV. Perhitungan Poin LRFM

\begin{tabular}{|l|l|l|l|l|l|}
\hline No & \multicolumn{1}{|c|}{ Nama } & Length & Recency & Frequency & \multicolumn{1}{|c|}{ Monetary } \\
\hline 1 & Adry82d & 31 & 29 & 28 & 3620000 \\
\hline 2 & Agi & 28 & 11 & 15 & 3750000 \\
\hline 3 & Alba property \& share & 17 & 17 & 16 & 1760000 \\
\hline 4 & April & 5 & 6 & 4 & 1000000 \\
\hline 5 & Gilang & 10 & 13 & 8 & 880000 \\
\hline 6 & Hendra Gunawan & 0 & 11 & 1 & 110000 \\
\hline 7 & Shindu & 12 & 16 & 11 & 3850000 \\
\hline 8 & Erwan & 23 & 220 & 23 & 2530000 \\
\hline 9 & Angga & 7 & 667 & 7 & 770000 \\
\hline
\end{tabular}

Setelah melakukan perhitungan poin pelanggan, dilanjutkan ke tahap keempat yaitu pengelompokkan pelanggan berdasarkan poin LRFM pelanggan tersebut. Pengelompokkan pelanggan dilakukan untuk melihat tingkatan loyalitas pelanggan kepada CV. Blitzspot yang dibagi dalam kategori pelanggan berdasarkan poin LRFM yang didapat. Pengelompokkan pelanggan dapat dilihat pada Tabel V. 
Tabel V. Hasil Pengelompokkan Pelanggan

\begin{tabular}{|l|l|l|}
\hline No & \multicolumn{1}{|c|}{ Nama } & \multicolumn{1}{|c|}{ Kategori Pelanggan } \\
\hline 1 & Adry82d & Pelanggan Loyal \\
\hline 2 & Agi & Pelanggan Potensial \\
\hline 3 & Alba property \& share & Pelanggan Baru \\
\hline 4 & April & Pelanggan Baru \\
\hline 5 & Gilang & Pelanggan Baru \\
\hline 6 & Hendra Gunawan & Pelanggan Baru \\
\hline 7 & Shindu & Pelanggan Baru \\
\hline 8 & Erwan & Konsumen Potensial \\
\hline 9 & Angga & Konsumen tidak potensial \\
\hline
\end{tabular}

Setelah pengelompokkan pelanggan, maka masuk ke tahapan terakhir yaitu Penetapan strategi bisnis atau layanan sesuai dengan pengelompokkan pelanggan. Stretagi bisnis ini nantinya akan diberitahukan kepada konsumen/pelanggan melalui e-mail dari CV. Blitzspot. Penetapan strategis bisnis atau layanan sesuai dengan kategori pelanggan dapat dlihat pada Tabel Vl.

Tabel VI. Strategi Bisnis atau Layanan Berdasarkan Kategori Pelanggan

\begin{tabular}{|l|l|l|}
\hline No & \multicolumn{1}{|c|}{ Kategori Pelanggan } & \multicolumn{1}{c|}{ Strategi } \\
\hline 1 & Pelanggan Loyal & $\begin{array}{l}\text { 1. Bonus 1 bulan tiap tahunnya, bila tetap memakai paket yang sama. } \\
\text { 2. Penerapan harga khusus bila pelanggan loyal tersebut ingin melakukan upgrade terhadap paket } \\
\text { yang dia miliki. }\end{array}$ \\
\hline 2 & Pelanggan Potensial & $\begin{array}{l}\text { 1. Pemotongan pembayaran harga paket sebesar 50\% untuk 1 bulan saja. } \\
\text { 2. Bila pelanggan potensial tersebut melakukan upgrade terhadap paket yang dia miliki, maka akan } \\
\text { diberikan potongan harga paket hasil upgrade sebesar 50\% di bulan pertama. }\end{array}$ \\
\hline 3 & Pelanggan Baru & $\begin{array}{l}\text { Memberikan pemberitahuan agar selalu menjadi pelanggan Blitzspot untuk menikmati pelayanan yang } \\
\text { lebih tinggi }\end{array}$ \\
\hline 4 & Konsumen Potensial & $\begin{array}{l}\text { Pemotongan harga paket yang akan diambil sebesar 50\% untuk bulan pertama, kepada konsumen } \\
\text { potensial yang ingin kembali menjadi pelanggan Blitzspot. }\end{array}$ \\
\hline 5 & Konsumen tidak potensial & Mempromosikan produk Blitzspot secara berkala, beserta pelayanan-pelayanan terbaru Blitzspot. \\
\hline
\end{tabular}

\section{KESIMPULAN}

Berdasarkan hasil pengujian dan pembahasan yang telah dibuat, maka dapat ditarik kesimpulan sebagai berikut:

1. Direktur Utama dapat menganalisis daya saing dengan menggunakan Berlian Porter untuk meningkatkan kualitas layanan terhadap pelanggan CV. Blitzspot.

2. CV. Blitzspot dapat menentukan strategi dalam mempertahankan konsumen yang memiliki potensi untuk menjadi pelanggan setia CV. Blitzspot dan mempertahankan pelanggan setia CV. Blitzspot.

3. Konsumen atau Pelanggan CV. Blitzspot dapat dengan mudah untuk mengetahui informasi seputar layanan-layanan baru yang akan diberikan oleh CV. Blitzspot.

\section{REFERENSI}

[1] Jogiyanto,. Analisis dan Desain Sistem Informasi, Yogyakarta: ANDI, 2010.

[2] Payne, Adrian, Handbook of CRM : Achieving Exellence in Customer Management, Burlington: Butterworth-Heinemann, 2005.

[3] Budiardjo, Eko K. dan Prasetyo, Ari, "KESAMAAN ANTARA FRONT-CRM DENGAN DYNAMIC-CRM SEBAGAI CUSTOMER RELATIONSHIP MANAGEMENT(CRM) FRAMEWORK", SESIND02008-ITS, 17(12)2008, 2008

[4] Buttle, Francis, "Customer Relationship Management: Concepts and Technologies," Elsevier: Butterworth-Heinemann, 2009.

[5] S.Winer, Russell, “A Framework For Customer Relationship Management," Jurnal California Management Review, volume 43, 89-105, 2001.

[6] Greenberg, Paul, CRM at The Speed Of Light: Social CRM 2.0 Strategies, Tools, and Techniques for Engaging Your Customers, New York: McGraw Hill, 2010.

[7] Sumihardjo, Tumar, Daya Saing Berbasis Potensi Daerah, Bandung: Fokusmedia, 2008.

[8] Djafri, Novianty, MANAJEMEN KEPEMIMPINAN KEPALA SEKOLAH: (Pengetahuan Manajemen, Efektivitas, Kemandirian Keunggulan Bersaing dan Kecerdasan Emosi), Yogyakarta: Deepublish, 2016.

[9] Suhartini dan Yuliawati, Evi, "FAKTOR-FAKTOR YANG MEMPENGARUHI ANALISIS DAYA SAING INDUSTRI BATIK BERBASIS DIAMOND PORTER MODELLING," Prosiding Seminar Nasional Multi Disiplin Ilmu \& Call for Papers Unisbank, 2015.

[10] Briyant, Derya, "Data Mining Using RFM Analysis, KnowledgeOriented Applications in Data Mining," Prof. Kimito Funatsu (Ed.), 2011. 